\title{
Psychological impact of COVID-19 on medical care workers in China
}

Ming-Yu Si ${ }^{1 \dagger}$, Xiao-You Su ${ }^{1 * \dagger}$ D, Yu Jiang ${ }^{1 *}$, Wen-Jun Wang ${ }^{2+}$, Xiao-Fen $\mathrm{Gu}^{3}$, Li Ma ${ }^{4}$, Jing Li ${ }^{5}$, Shao-Kai Zhang ${ }^{6}$, Ze-Fang Ren ${ }^{7}$, Ran Ren ${ }^{8}$, Yuan-Li Liu ${ }^{9}$ and You-Lin Qiao ${ }^{10^{*}}$

\begin{abstract}
Background: Medical care workers experienced unprecedented levels of workload and pressure since the outbreak of coronavirus disease 2019 (COVID-19). Little is known about its exact impact on medical care workers and related factors in China. This study aims to identify the psychological impact of COVID-19 on medical care workers in China.

Methods: From February 23 to March 5, 2020, a cross-sectional survey was conducted among 863 medical care workers from seven provinces in China using standard questionnaires measuring adverse psychological outcomes including Impact of Event Scale-6 (IES-6), Depression, Anxiety and Stress Scale(DASS)and related psychosocial factors like perceived threat, social support and coping strategies. Exploratory Factor analysis was performed to identify the dimensions of perceived threat by study participants. Multivariate regression was used to examine the determinants of adverse psychological outcomes.

Results: Posttraumatic stress (PTS) were prevalent in this sample of health care professionals, and $40.2 \%$ indicated positive screens for significant posttraumatic stress disorder symptoms. The proportion of having mild to extremely severe symptoms of depression, anxiety and stress were 13.6, 13.9 and 8.6\%, respectively. Perceived threat and passive coping strategies were positively correlated to PTS and DASS scores, while perceived social support and active coping strategies were negatively correlated to DASS scores. Nurses were more likely to be anxious than others among medical care workers during the COVID-19 epidemic.

Conclusions: Adverse psychological symptoms were prevalent among medical care workers in China during the COVID-19 epidemic. Screening for adverse psychological outcomes and developing corresponding preventive measures would be beneficial in decreasing negative psychological outcomes.
\end{abstract}

Keywords: COVID-19, Medical care worker, China, Psychological, Posttraumatic stress disorder, Depression, Anxiety, Stress

\footnotetext{
* Correspondence: suxiaoyou@hotmail.com; jiangyu@pumc.edu.cn; qiaoy@cicams.ac.cn

${ }^{+}$Ming-Yu Si, Xiao-You Su and Wen-Jun Wang are joint first authors.

'Department of Epidemiology and Biostatistics, School of Population

Medicine and Public Health, Chinese Academy of Medical Sciences and

Peking Union Medical College, Beijing, China

${ }^{10}$ Department of Cancer Epidemiology, National Cancer Center/National Clinical Research Center for Cancer/Cancer Hospital, Chinese Academy of Medical Sciences and Peking Union Medical College, 17 South Panjiayuan, Chaoyang District, Beijing, China

Full list of author information is available at the end of the article
}

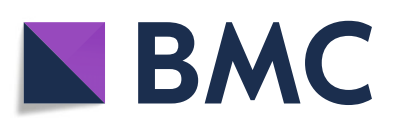

(c) The Author(s). 2020 Open Access This article is licensed under a Creative Commons Attribution 4.0 International License, which permits use, sharing, adaptation, distribution and reproduction in any medium or format, as long as you give appropriate credit to the original author(s) and the source, provide a link to the Creative Commons licence, and indicate if changes were made. The images or other third party material in this article are included in the article's Creative Commons licence, unless indicated otherwise in a credit line to the material. If material is not included in the article's Creative Commons licence and your intended use is not permitted by statutory regulation or exceeds the permitted use, you will need to obtain permission directly from the copyright holder. To view a copy of this licence, visit http://creativecommons.org/licenses/by/4.0/ The Creative Commons Public Domain Dedication waiver (http://creativecommons.org/publicdomain/zero/1.0/) applies to the data made available in this article, unless otherwise stated in a credit line to the data. 


\section{Background}

There have been 3090445 cases of coronavirus disease 2019 (COVID-19) and 217769 death reported worldwide as of April 30, 2020 [1]. In China alone, there were reports of more than 84373 COVID-19 cases with 4643 deaths [1]. After the rapid spread of the outbreak to many countries in the world, the World Health Organization (WHO) declared the COVID-19 outbreak as a pandemic on March 11, 2020. Public health intervention nationwide and quarantine had been implemented in most of the countries in the past months.

There is a wide consensus that the outbreak of an infectious disease is often linked with adverse psychological outcomes. Containment measures, including compulsory- or self-quarantine and social distancing, especially if protracted, may increase the risk of mental disorders, such as depression, anxiety, thought disorders and post traumatic stress (PTS) [2]. Compared with the general population, medical care workers are more likely to experience a wide range of negative psychological impact following an emergency or disaster. Severe emotional stress had been reported during or after the infectious diseases outbreak among medical care workers in previous studies, including the 2003 severe acute respiratory syndrome (SARS) epidemic [3], 2014 Ebola virus disease and 2015 Middle East respiratory syndrome (MERS) outbreak [4, 5].

It has been shown that the medical care workers experienced a high level of emotional stress, anxiety, depression and PTS during or even after the outbreak of the infectious diseases [6]. Acute stress disorder (ASD) has similar symptoms to post traumatic stress disorder (PTSD), is diagnosed three days to 1-month post trauma and is a good predictor of PTSD [7]. In a study among medical care workers in a Taiwan hospital during the outbreak of SARS, 5\% suffered from an ASD [8]. Given the magnitude of pandemic of COVID-19 and the stress undergone by the medical care workers, adverse psychological outcomes are expected to occur among them, especially those on the front line. Up to now, little is known about the psychological impact of the COVID-19 pandemic on medical care workers in the most severely affected countries, including China.

Adverse psychological outcomes among medical care workers are usually determined by a variety of factors during an outbreak of infectious disease with high level of mortality, including uncertain quarantine duration, inadequate medical supplies, fears of infection, stigma and discrimination etc. [2, 9]. Meanwhile, the support they gained from others and the coping strategies they adopted during the event had been reported to be associated with their psychological status during the epidemic of infectious disease [5]. Less support and more negative coping strategies were proved to be common predictors of both acute and chronic PTS and other mental health problems $[10,11]$. By understanding the psychological outcomes caused by an outbreak on medical care workers and studying the mechanism underneath, effective intervention and treatment can be developed and provided to this population, hence to improve their psychological wellbeing.

The present study aimed to investigate the presence of adverse psychological outcome, anxiety, depression and PTS, experienced by medical care workers during the COVID-19 outbreak and assess the associated factors, to better understand the psychological suffering of medical care workers and provide clues of developing intervention to alleviate the psychological stress of this population.

\section{Methods}

\section{Sampling and data collection}

Study participants were recruited from hospitals of seven geographical regions in China, located in north, south, east, central, northwest, northeast and southwest part of China. Clinical and administrative staff in these hospitals were invited to the study. They filled out an online selfadministered structured questionnaire from February 23 to March 5, 2020. The questionnaires were disseminated and administered by a university staff in each of the geographical regions. Two pairs of questions were embedded in the survey questionnaire for quality control: (1) For basic information quality control, gender question was asked twice in the questionnaire in different places; (2) two reverse matching questions 'Do you agree that influenza or pneumonia vaccine can prevent new COVID-19' and 'Do you agree that influenza or pneumonia vaccines cannot prevent COVID-19' in the questionnaire. Only the questionnaires that pass the above triple quality control were included in the statistical analysis. Ethical approval for the survey was obtained from the Ethics Committee of Jining Medical University of Shandong Province on February 12, 2020.

\section{Measurements}

Survey questions included demographic characteristics (i.e., age, gender, education, marital status and occupation), general health status, variables related to the COVID-19 (e.g. whether ever been quarantined, level of concern to the outbreak), perceived threat of COVID19, perceived stress, anxiety, depression and PTS, perceived social support and coping strategies.

\section{Impact of event Scale-6 (IES-6)}

The impact of event Scale-6 (IES-6) was an abbreviated version of The Impact of Event Scale-revised (IES-R), and it includes three current symptom subscales of posttraumatic stress disorder (PTSD), including intrusion, 
hyper-arousal and avoidance. The six items of the IES-6 were proved correlated highly with the IES-R and the Post Traumatic Stress Disorder Check List Civilian version (PCL), and was suggested to be a robust brief measure of posttraumatic stress reactions both in epidemiological studies and in clinical practice [12]. IES-R was validated among Chinese population and used for measuring the psychological impact after exposure to a crisis situation within one week of exposure [13]. In this study, the Cronbach's alpha of IES-6 was 0.81 .

\section{Depression, anxiety and stress scale (DASS)}

The Chinese brief version of the Depression, Anxiety, and Stress Scale (DASS-21) was used to measure psychological distress of the study participants. Study participants gave item ratings according to their experience over the past weeks on a 4-point Likert rating scale. It consists of three self-reported subscales (each with seven items), measuring depression, anxiety, and stress [14, 15]. The Chinese version of DASS had been validated among various Chinese population [16, 17]. The Chronbach's alpha of the three subscales of DASS were 0.83, 0.80 and 0.82 , and 0.92 for the total DASS in this study.

\section{Perceived threat}

Participants' perceived threat by COVID-19 was measured by 8 items developed based on the earlier studies: 'I am afraid of being infected by COVID-19', 'I'm anxious to be shifted to the ward for COVID-19 patients', 'I'm worried about being quarantined or isolated', 'My job puts me at a high risk of being infected by COVID-19', 'My close contacts are at high risk of being infected due to my job', 'My close friends and relatives are worried that I might transmit the virus to them', 'I'm distanced by others due to my job', 'I'm stigmatized by others due to my job'. For each individual item, the answer is on a 5-point Likert scale ('strongly disagree' to 'strongly agree'), and a higher total score indicated a greater perceived threat by the COVID-19 outbreak. The Chronbach's alpha of the 8 -item perceived threat was 0.81 .

\section{The perceived social support scale (PSSS)}

PSSS is a validated 12-item instrument, assessing perceived support obtained from family, friends, and significant others [18]. The scores range from 12 to 84, with a higher score indicating a higher level of perceived support. The Chinese version of the PSSS was validated and showed a good internal reliability (Cronbach's alpha was 0.89) [19]. In this study, the Cronbach's alpha value was 0.94 .

\section{Simplified coping style questionnaire}

Coping style was assessed by the SCSQ, a 20-item scale with scores ranging from 0 to 3 on each item. SCSQ was developed based on the Ways of Coping questionnaire by Folkman and Lazarus [20, 21]. The SCSQ measures two coping styles: active coping (AC) and passive coping $(\mathrm{PC})$, focusing on problem solving and emotional distress, respectively [22]. The scale has shown high internal consistency for both active coping styles (Cronbach's $\alpha=0.89$ ) and passive coping styles (Cronbach's $\alpha=0.78$ ). In this study, the Cronbach's alpha coefficients for the two dimensions of SCSQ were 0.86 and 0.80 , respectively.

\section{Statistical analysis}

The internal consistency of the scales was assessed by using Cronbach's alpha coefficients. Exploratory factor analysis, using principal component and varimax rotation methods, was performed Exploratory Factor analysis to uncover the underlying dimensions of the perceived threat items. The prevalence of psychological symptoms were derived according to the cut-off values suggested in previous studies. Descriptive statistics were calculated for sociodemographic characteristics and variables related to the COVID-19 outbreak. Linear regressions were used to calculate the univariate associations between sociodemographic characteristics, variables related to the COVID-19 outbreak, and psychological outcomes (the IES-6 score and the subscales of the DASS). Pearson correlation were performed to assess the associations between adverse psychological outcomes and the potential psychosocial factors of the perceived threat. Multiple linear regression was performed to explore adverse psychological health status and their potential factors by adjusting the variables significant in univariate analysis at $P \leq 0.10$. Statistical significance of all two-tailed tests was set at $P \leq 0.05$. The SPSS 22.0 (IBM SPSS Statistics, New York, United States) was used for the statistical analysis.

\section{Results}

\section{Participants' characteristics}

Of the 1136 medical care workers we invited to the study, 863 completed the questionnaire survey (response rate $=76.0 \%$ ). Table 1 presents the sample characteristics by adverse psychological outcomes. $29.3 \%$ were male, $77.3 \%$ were at age less than $40,64.9 \%$ were currently married, $88.0 \%$ had a college or above educational background, $43.7 \%$ had a monthly income less than Chinese yuan 6000 (around United States dollar 850), 43.7\% were doctors, $24.4 \%$ were nurses, $6.0 \%$ ever had chronic diseases, $7.4 \%$ were current tobacco users and $32.6 \%$ were current alcohol users. In addition, $25.6 \%$ had ever been quarantined or isolated during the outbreak, $16.8 \%$ were 
Table 1 Association between demographics and adverse psychological outcomes of the COVID-19 outbreak $(n=863)$

\begin{tabular}{|c|c|c|c|c|c|c|c|c|c|}
\hline \multirow[t]{2}{*}{ Variables } & \multirow[t]{2}{*}{$\boldsymbol{n}(\%)$} & \multicolumn{2}{|c|}{ Impact of event } & \multicolumn{2}{|c|}{ Depression } & \multicolumn{2}{|c|}{ Anxiety } & \multicolumn{2}{|l|}{ Stress } \\
\hline & & $\bar{\beta}$ & $P$ & $\bar{\beta}$ & $P$ & $\beta$ & $P$ & $\beta$ & $P$ \\
\hline \multicolumn{10}{|l|}{ Gender } \\
\hline Male & $253(29.3 \%)$ & -0.617 & 0.091 & 0.520 & 0.188 & -0.135 & 0.714 & 0.169 & 0.730 \\
\hline Female & $610(70.7 \%)$ & \multicolumn{2}{|l|}{ Reference } & \multicolumn{2}{|c|}{ Reference } & \multicolumn{2}{|c|}{ Reference } & \multicolumn{2}{|c|}{ Reference } \\
\hline \multicolumn{10}{|l|}{ Age (Years) } \\
\hline$\leq 29$ & $277(32.1 \%)$ & 0.233 & 0.754 & -0.473 & 0.557 & 0.954 & 0.202 & -1.089 & 0.274 \\
\hline $30-39$ & $390(45.2 \%)$ & -0.410 & 0.572 & -0.683 & 0.385 & 0.414 & 0.517 & -0.968 & 0.320 \\
\hline $40-49$ & 145 (16.8\%) & 0.480 & 0.545 & 0.238 & 0.782 & 0.531 & 0.506 & -0.008 & 0.994 \\
\hline$\geq 50$ & $51(5.9 \%)$ & \multicolumn{2}{|l|}{ Reference } & \multicolumn{2}{|c|}{ Reference } & \multicolumn{2}{|c|}{ Reference } & \multicolumn{2}{|c|}{ Reference } \\
\hline \multicolumn{10}{|l|}{ Marital status } \\
\hline Currently not married & $303(35.1 \%)$ & -0.230 & 0.508 & -0.182 & 0.630 & 0.475 & 0.174 & -0.397 & 0.395 \\
\hline Currently married & $560(64.9 \%)$ & \multicolumn{2}{|l|}{ Reference } & \multicolumn{2}{|c|}{ Reference } & \multicolumn{2}{|c|}{ Reference } & \multicolumn{2}{|c|}{ Reference } \\
\hline \multicolumn{10}{|l|}{ Education } \\
\hline Technical secondary or below & $104(12.0 \%)$ & -0.198 & 0.722 & 0.170 & 0.778 & 0.431 & 0.441 & 0.084 & 0.910 \\
\hline College & $466(54.0 \%)$ & 0.372 & 0.306 & -0.134 & 0.733 & 0.450 & 0.219 & -0.206 & 0.672 \\
\hline Advanced degree & $293(34.0 \%)$ & \multicolumn{2}{|l|}{ Reference } & \multicolumn{2}{|c|}{ Reference } & \multicolumn{2}{|c|}{ Reference } & \multicolumn{2}{|c|}{ Reference } \\
\hline \multicolumn{10}{|l|}{ Monthly income (CNY) } \\
\hline$<6000$ & $377(43.7 \%)$ & -0.117 & 0.782 & -0.158 & 0.728 & 0.442 & 0.296 & 0.164 & 0.771 \\
\hline 6000-9999 & $277(32.1 \%)$ & 0.391 & 0.381 & -0.445 & 0.358 & 0.066 & 0.883 & -0.061 & 0.919 \\
\hline$\geq 10000$ & $209(24.2 \%)$ & Reference & & Referer & & Refere & & Referer & \\
\hline Occupation & & & & & & & & & \\
\hline Doctor & $377(43.7 \%)$ & 0.607 & 0.114 & 0.597 & 0.154 & -0.046 & 0.905 & 0.398 & 0.443 \\
\hline Nurse & $211(24.4 \%)$ & 1.520 & 0.001 & 0.699 & 0.148 & 1.283 & 0.004 & 0.957 & 0.110 \\
\hline Other health worker & $275(31.9 \%)$ & Reference & & Referer & & Refere & & Referer & \\
\hline Ever had chronic disease(s) & & & & & & & & & \\
\hline Yes & $52(6.0 \%)$ & 1.800 & 0.010 & 2.324 & 0.002 & 1.782 & 0.011 & 2.797 & 0.003 \\
\hline No & $811(94.0 \%)$ & Reference & & Referer & & Refere & & Referer & \\
\hline Current tobacco user & & & & & & & & & \\
\hline Yes & $64(7.4 \%)$ & -1.426 & 0.024 & -0.324 & 0.637 & -0.733 & 0.250 & -0.711 & 0.403 \\
\hline No & 799 (92.6\%) & Reference & & Referer & & Refere & & Referer & \\
\hline Current alcohol user & & & & & & & & & \\
\hline Yes & $281(32.6 \%)$ & 0.262 & 0.460 & 0.791 & 0.039 & 0.475 & 0.182 & 0.646 & 0.174 \\
\hline No & $582(67.4 \%)$ & Reference & & Referer & & Refere & & Referer & \\
\hline
\end{tabular}

frontline medical workers, $74.0 \%$ were highly concerned about the epidemic. Respectively 95.0, 4.2 and $1.3 \%$ had confirmed cases in their living city, community and relatives and friends (Table 1 and Table 2).

\section{Factor loadings of perceived threat items and their psychometric properties}

EFA on the 8 items of perceived threat yielded 3 factors (explaining $76.9 \%$ of the total variance; $\mathrm{KMO}=0.75$ ), with satisfactory eigenvalue and factor loadings (eigenvalue $>1$ and factor loading $>0.45$ ) [23]. The three factors identified from the EFA assess respondents' level of perceived threat with respect to stigmatization/distancing, fears of infection and high-risk job, with Chronbach's alpha of $0.81,0.78$ and 0.79 (Table 3). The overall score of perceived threat and the extracted factors were calculated by summing up all item scores and were proved all significantly correlated with the scores of IES-6 and three subscales of DASS (Table 4).

\section{Prevalence of psychological symptoms and perceived threat}

IES-6 scale was used to measure the posttraumatic stress of COVID-19 outbreak, which revealed a sample mean 
Table 2 Association between variables related to the COVID-19 outbreak and adverse psychological outcomes $(n=863)$

\begin{tabular}{|c|c|c|c|c|c|c|c|c|c|}
\hline \multirow[t]{2}{*}{ Variables } & \multirow[t]{2}{*}{$n(\%)$} & \multicolumn{2}{|c|}{ Impact of event } & \multicolumn{2}{|c|}{ Depression } & \multicolumn{2}{|c|}{ Anxiety } & \multicolumn{2}{|l|}{ Stress } \\
\hline & & $\beta$ & $P$ & $\beta$ & $P$ & $\beta$ & $P$ & $\beta$ & $P$ \\
\hline \multicolumn{10}{|c|}{ Ever been quarantined or isolated } \\
\hline Yes & $221(25.6 \%)$ & 0.407 & 0.285 & 0.776 & 0.059 & 0.308 & 0.421 & 0.610 & 0.232 \\
\hline No & $642(74.4 \%)$ & Reference & & Referer & & Refere & & Refere & \\
\hline \multicolumn{10}{|c|}{ Duty during the epidemic } \\
\hline Front line workers & $145(16.8 \%)$ & 0.156 & 0.725 & 0.012 & 0.980 & 0.817 & 0.067 & 0.938 & 0.115 \\
\hline Second line or others & $718(83.2 \%)$ & Reference & & Referen & & Refere & & Refere & \\
\hline \multicolumn{10}{|l|}{ Levels of concern } \\
\hline High concern & $639(74.0 \%)$ & 1.704 & 0.000 & 0.218 & 0.595 & 0.163 & 0.669 & 1.232 & 0.015 \\
\hline Less concern & $224(26.0 \%)$ & Reference & & Referer & & Refere & & Refere & \\
\hline \multicolumn{10}{|c|}{ Confirmed cases in the living city } \\
\hline Yes & $820(95.0 \%)$ & 0.983 & 0.197 & -0.014 & 0.986 & 0.147 & 0.848 & 1.206 & 0.239 \\
\hline No or not sure & $43(5.0 \%)$ & Reference & & Referer & & Refere & & Refere & \\
\hline \multicolumn{10}{|c|}{ Confirmed cases in the living community } \\
\hline Yes & $36(4.2 \%)$ & 0.249 & 0.764 & 2.082 & 0.020 & 2.854 & 0.001 & 2.542 & 0.022 \\
\hline No or not sure & $827(95.8 \%)$ & Reference & & Referer & & Refere & & Refere & \\
\hline \multicolumn{10}{|c|}{ Confirmed cases among relatives and friends } \\
\hline Yes & $11(1.3 \%)$ & 3.045 & 0.039 & 5.265 & 0.001 & 3.563 & 0.017 & 7.808 & 0.000 \\
\hline No & 852 (98.7\%) & Reference & & Referen & & Refere & & Refere & \\
\hline
\end{tabular}

score of 8.54 (standard deviation $=4.87$ ) (data not tabulated). The IES- 6 with a cutoff of 10 was used as a proximate measure of PTS, which is considered to have the best overall efficiency [12], and 347 (40.2\%) were considered to meet the clinical concern of PTSD. $97.9 \%$ of the respondents had one or more PTS symptoms. The most severe PTS domain among the respondents was intrusion: 'I thought about it when I did not mean to' (93.7\%) and 'Other things kept making me think about it'
(76.4\%), then the hyperarousal and avoidance domain (Fig. 1 and Fig. 2). DASS severity ratings of the respondents were presented in Fig. 1. The proportion of having mild to extremely severe symptoms of depression, anxiety and stress were 13.6, 13.9 and 8.6\%, respectively.

In total, 'Fears of infection' and 'Doing high-risk job' were the mostly perceived threat by the participants. While 525 participants (60.8\%) reported 'I am afraid of being infected by COVID-19', only 159 (18.4\%)

Table 3 Factor loadings of perceived threat items among medical care workers $(n=863)$

\begin{tabular}{llll}
\hline Perceived threat (Items) & Factor1 & Factor 2 & $\begin{array}{l}\text { Factor } 3 \\
\text { High-risk job }\end{array}$ \\
\hline Afraid of being infected by COVID-19 & Stigmatization /distancing & 0.390 \\
Anxious to be shifted to the ward for COVID-19 & -0.057 & 0.704 & 0.057 \\
Worried about being quarantined or isolated & 0.213 & 0.848 & 0.860 \\
My job puts me at a high risk of being infected & 0.138 & 0.297 & 0.820 \\
My close contacts are at high risk of being infected & 0.119 & 0.090 & 0.888 \\
Friends and relatives are worried to be infected by me & 0.182 & 0.627 & 0.110 \\
I'm distanced by others due to my job & 0.916 & 0.142 & 0.498 \\
I'm stigmatized by others due to my job & 0.901 & 0.087 & 0.113 \\
Eigenvalue & 2.158 & 2.091 & 0.079 \\
Cumulative \% of variance explained & 26.971 & 53.111 & 1.899 \\
Cronbach's alpha & 0.812 & 0.780 & 76.845 \\
\hline
\end{tabular}

Exploratory factor analysis, using principle component analysis for factor extraction (with varimax rotation) Factor 1-3 addressed threat due to stigmatization/distancing, fears of infection and high-risk job 
Table 4 Pearson correlation between perceived threat, perceived social support, coping style and adverse psychological outcomes $(n=863)$

\begin{tabular}{|c|c|c|c|c|c|c|c|c|}
\hline \multirow[t]{2}{*}{ Variables } & \multicolumn{2}{|c|}{ Impact of event } & \multicolumn{2}{|c|}{ Depression } & \multicolumn{2}{|c|}{ Anxiety } & \multicolumn{2}{|l|}{ Stress } \\
\hline & $\beta$ & $P$ & $\beta$ & $P$ & $\beta$ & $P$ & $\beta$ & $P$ \\
\hline Perceived threat & 0.342 & 0.000 & 0.284 & 0.000 & 0.234 & 0.000 & 0.353 & 0.000 \\
\hline Stigmatization/distancing & 0.517 & 0.000 & 0.674 & 0.000 & 0.548 & 0.000 & 0.761 & 0.000 \\
\hline Fears of infection & 0.455 & 0.000 & 0.339 & 0.000 & 0.260 & 0.000 & 0.377 & 0.000 \\
\hline High-risk job & 0.666 & 0.000 & 0.560 & 0.000 & 0.529 & 0.000 & 0.772 & 0.000 \\
\hline Perceived social support & -0.003 & 0.856 & -0.109 & 0.000 & -0.106 & 0.000 & -0.130 & 0.000 \\
\hline Active coping (AC) & 0.063 & 0.048 & -0.127 & 0.000 & -0.134 & 0.000 & -0.172 & 0.000 \\
\hline Passive coping (PC) & 0.234 & 0.000 & 0.309 & 0.000 & 0.247 & 0.000 & 0.318 & 0.000 \\
\hline
\end{tabular}

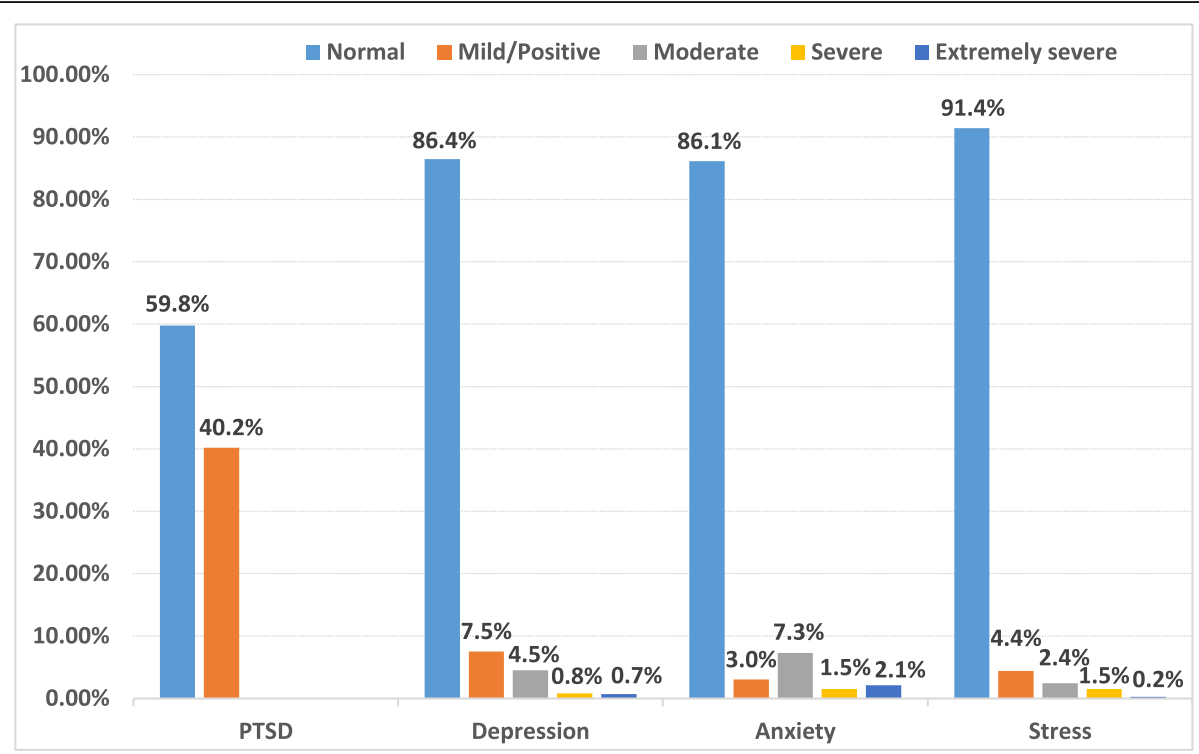

\begin{tabular}{ccccc}
\hline Symptoms & PTSD & Depression & Anxiety & Stress \\
\hline Normal & $59.79 \%$ & $86.44 \%$ & $86.10 \%$ & $91.43 \%$ \\
Mild/Positive & $40.21 \%$ & $7.53 \%$ & $3.01 \%$ & $4.40 \%$ \\
Moderate & - & $4.52 \%$ & $7.30 \%$ & $2.43 \%$ \\
Severe & - & $0.81 \%$ & $1.51 \%$ & $1.51 \%$ \\
Extremely severe & - & $0.70 \%$ & $2.09 \%$ & $0.23 \%$ \\
\hline
\end{tabular}

Fig. 1 Percentage of participants with mild to extremely severe depression, anxiety and stress, and IES-6 scores more than the cut-off 10. PTSD: Post traumatic stress disorder; IES: Impact of event scale 


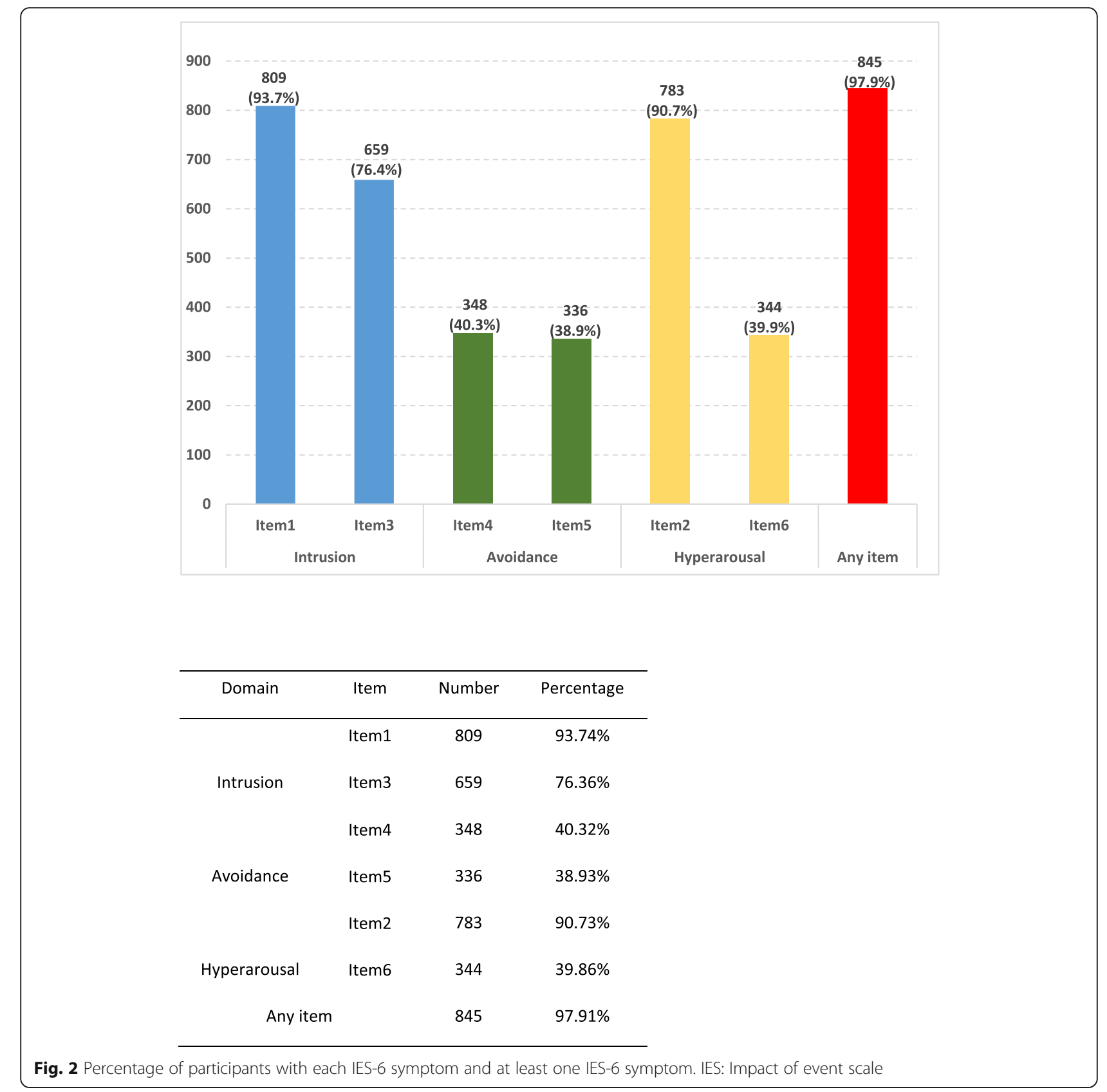

responded that 'I'm anxious to be shifted to the ward for COVID-19 patients'. In addition, 420 (48.7\%) agreed 'My close contacts are at higher risk of being infected due to my job', and 417 participants (48.3\%) agreed 'My job puts me at a high risk of being infected by COVID-19'. $78.5 \%$ of the participants reported have at least one out of the 8 perceived threat items (Fig. 3).

\section{Bivariate correlates of adverse psychological outcomes}

Those who were nurses $(\beta=1.52, P=0.001)$, ever had chronic diseases $(\beta=1.80, P=0.010)$, had high concern to the outbreak ( $\beta=1.70, P=0.000)$, and had confirmed cases among their relatives and friends $(\beta=3.05, P=$ 0.039 ) were more likely to have PTS symptoms. Those who were current tobacco user were less likely to have PTS symptoms $(\beta=-1.43, \quad P=0.024) \quad$ (Table 1 and Table 2).

Those who ever had chronic diseases $(\beta=2.32, P=$ $0.002)$, who were current alcohol user $(\beta=0.79, P=$ $0.039)$, had confirmed cases in their living community $(\beta=2.08, P=0.020)$ and had confirmed cases among their relatives and friends $(\beta=5.27, P=0.001)$ were more 


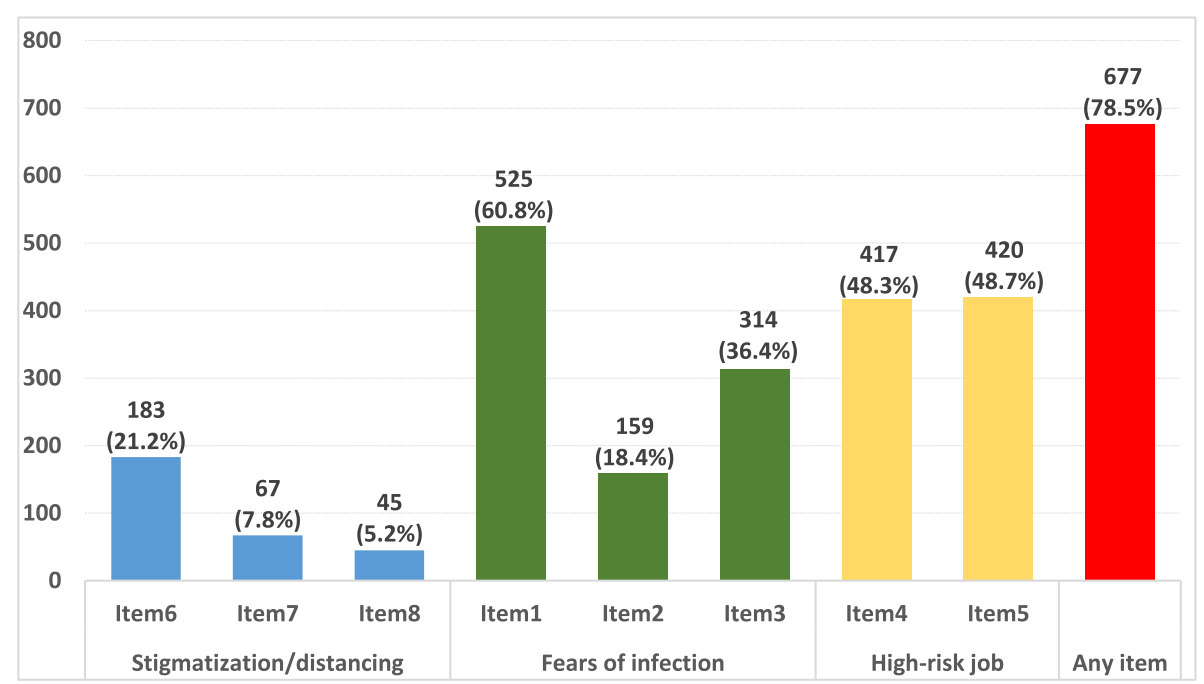

\begin{tabular}{lccc}
\hline Domain & Item & Number & \\
\hline Stigmatization/distancing & Item6 & 183 & $21.21 \%$ \\
& Item7 & 67 & $7.76 \%$ \\
& Item8 & 45 & $5.21 \%$ \\
Fears of infection & Item1 & 525 & $60.83 \%$ \\
& Item2 & 159 & $18.42 \%$ \\
& Item3 & 314 & $36.38 \%$ \\
High-risk job & Item4 & 417 & $48.32 \%$ \\
& Item5 & 420 & $48.67 \%$ \\
Any item & & 677 & $78.45 \%$ \\
\hline
\end{tabular}

Fig. 3 Percentage of participants with each perceived threat and at least one threat

likely to have depression symptoms. Those who were nurses $(\beta=1.28, P=0.004)$, ever had chronic diseases $(\beta=1.78, P=0.011)$ and had confirmed cases in their living community $(\beta=2.85, P=0.001)$ and had confirmed cases among their relatives and friends $(\beta=3.56, P=$ $0.017)$ were more likely to have anxiety symptoms. Those who ever had chronic diseases $(\beta=2.80, P=$ $0.003)$, had high concern to the outbreak $(\beta=1.23, P=$ $0.015)$, had confirmed cases in their living community $(\beta=2.54, P=0.022)$ and had confirmed cases among their relatives and friends $(\beta=7.81, P=0.000)$ were more likely to have stress symptoms.

\section{Pearson correlation between adverse psychological} symptoms and perceived threat, perceived social support and coping style

The IES- 6 and DASS score were correlated with almost all proposed psychosocial variables including overall score and scores of the three domains of perceived threat, perceived social support, and two forms of coping strategies in anticipated directions. The adverse psychological symptoms were positively associated with perceived threat and passive coping strategies, while negatively associated with perceived social support and active coping strategies, except the correlation of IES-6 
with perceived social support $((\beta=-0.00, P=0.856)$ and with active coping $(\beta=0.06, P=0.048)$ (Table 4$)$.

\section{Multivariate correlates of psychological symptoms}

Compare to other groups, nurses were more likely to have anxiety symptoms $(\beta=0.93, P=0.026)$ (Table 5$)$. Participants who were current tobacco user were less likely to have PTS symptoms $(\beta=-1.55, P=0.015)$. Level of concern to the outbreak was positively correlated with PTS $(\beta=1.49, P=0.000)$ and stress symptoms $(\beta=1.22$, $P=0.009$ ). Those who had confirmed cases in their living community were more likely to be anxious $(\beta=1.82$, $P=0.018$ ), and who have confirmed cases among relatives and friends were more likely to have depression

Table 5 Results of multiple linear regression analysis on IES-6 and DASS ( $n=863)$

\begin{tabular}{|c|c|c|c|c|c|c|c|c|}
\hline \multirow[t]{2}{*}{ Variables } & \multicolumn{2}{|c|}{ Impact of event } & \multicolumn{2}{|c|}{ Depression } & \multicolumn{2}{|l|}{ Anxiety } & \multicolumn{2}{|l|}{ Stress } \\
\hline & $\bar{\beta}$ & $P$ & $\beta$ & $P$ & $\bar{\beta}$ & $P$ & $\bar{\beta}$ & $P$ \\
\hline \multicolumn{9}{|l|}{ Gender } \\
\hline Male & -0.140 & 0.721 & - & & - & & - & \\
\hline Female & Reference & & & & & & & \\
\hline \multicolumn{9}{|l|}{ Occupation } \\
\hline Doctor & -0.206 & 0.565 & - & & -0.473 & 0.187 & - & \\
\hline Nurse & 0.549 & 0.201 & & & 0.930 & 0.026 & & \\
\hline Other health worker & Reference & & & & Referen & & & \\
\hline \multicolumn{9}{|l|}{ Ever had chronic disease(s) } \\
\hline Yes & 1.174 & 0.068 & 1.198 & 0.080 & 1.067 & 0.095 & 1.357 & 0.111 \\
\hline No & Reference & & Referenc & & Referen & & Referen & \\
\hline \multicolumn{9}{|l|}{ Current tobacco user } \\
\hline Yes & -1.549 & 0.015 & - & & - & & - & \\
\hline No & Reference & & & & & & & \\
\hline \multicolumn{9}{|l|}{ Current alcohol user } \\
\hline Yes & - & & 0.344 & 0.323 & - & & - & \\
\hline No & & & Referenc & & & & & \\
\hline \multicolumn{9}{|c|}{ Ever been quarantined or isolated } \\
\hline Yes & - & & 0.588 & 0.111 & - & & - & \\
\hline No & & & Referenc & & & & & \\
\hline \multicolumn{9}{|l|}{ Levels of concern } \\
\hline Highly concerned & 1.488 & 0.000 & - & & - & & 1.224 & 0.009 \\
\hline Less concerned & Reference & & & & & & Referen & \\
\hline \multicolumn{9}{|c|}{ Confirmed cases in the living community } \\
\hline Yes & - & & 0.639 & 0.436 & 1.822 & 0.018 & 0.666 & 0.515 \\
\hline No or not sure & & & Referenc & & Referen & & Referen & \\
\hline \multicolumn{9}{|c|}{ Confirmed cases among relatives and friends } \\
\hline Yes & 2.071 & 0.125 & 3.701 & 0.011 & 1.792 & 0.190 & 5.747 & 0.002 \\
\hline No & Reference & & Referenc & & Referen & & Referen & \\
\hline \multicolumn{9}{|l|}{ Perceived threat } \\
\hline Stigmatization/distancing & 0.282 & 0.000 & 0.416 & 0.000 & 0.306 & 0.000 & 0.433 & 0.000 \\
\hline Fears of infection & 0.251 & 0.000 & 0.099 & 0.116 & 0.044 & 0.448 & 0.052 & 0.495 \\
\hline High-risk job & 0.285 & 0.001 & 0.231 & 0.010 & 0.272 & 0.001 & 0.428 & 0.000 \\
\hline Perceived social support & - & & -0.064 & 0.000 & -0.072 & 0.000 & -0.083 & 0.000 \\
\hline Active coping (AC) & 0.031 & 0.303 & -0.106 & 0.003 & -0.106 & 0.001 & -0.152 & 0.001 \\
\hline Passive coping (PC) & 0.172 & 0.000 & 0.274 & 0.000 & 0.220 & 0.000 & 0.286 & 0.000 \\
\hline
\end{tabular}

\# Impact of event: R-Squared $\left(R^{2}\right)=0.193$, Adjusted R-Squared $\left(\mathrm{AR}^{2}\right)=0.182, P=0.000$; Depression: $R^{2}=0.217, \mathrm{AR}^{2}=0.206, P=0.000 ;$ Anxiety: $R^{2}=0.199, \mathrm{AR}^{2}=$ $0.189, P=0.000$; Stress: $R^{2}=0.200, \mathrm{AR}^{2}=0.191, P=0.000$ 
$(\beta=3.70, P=0.011)$ and stress symptoms $(\beta=5.75, P=$ 0.002). Apart from the 'Fears of infection', other two dimension of perceived threat were positively associated with the PTS and DASS (value of $\beta$ and $P$ see Table 5), those with more fears of infection were more likely to have PTS $(\beta=0.25, P=0.000)$. Three dimensions of Perceived threat and passive coping strategies were positively related to both PTS $(\beta=0.28,0.25,0.29$ and 0.31 , $P=0.000$ ) and DASS symptoms (value of $\beta$ and $P$ see Table 5). Perceived social support and active coping were negatively related to DASS symptoms (value of $\beta$ and $P$ see Table 5). Those adopted passive coping strategies were more likely to have PTS and DASS.

\section{Discussion}

The results of our study revealed a high prevalence of PTS among Chinese medical care workers during the outbreak of COVID-19 virus. Nearly half of the participants suffered from PTS meeting clinical cut-off of PTSD and 97.9\% experienced at least one PTSD symptoms, which was much higher than in other population in the same study (34.0 and $94.0 \%$ respectively among university students, data not tabulated). The rate was also out of the range of $10-27 \%$ probable and clinical PTSD diagnosis reported in Ebola epidemic during 2014-2016 in general population [9] and in SARS outbreak among medical care workers in 2003 [24]. Compare to the PTS symptoms, the prevalence of depression (13.6\%) measured by DASS-21 were lower, but still significantly higher than the all age prevalence rate of $3.2 \%$ in Chinese population in recent decades [25].

Compared to the results of a multinational study on psychological impact of COVID-19 outbreak among health care professionals using the similar measurements, the proportion of PTSD symptoms, depression, anxiety, and stress were relatively higher in this study than in Singapore and in India, especially the prevalence of PTSD symptoms [26]. This difference may be explained from following aspects: Firstly, our study was conducted between February 23 to March 5, 2020, which lasted only two weeks at the beginning of the outbreak, while Chew's study was carried out between February 19 to April 17, 2020, which lasted almost two months. In February 2020, China was the most affected country in the world by the COVID-19. Lack of knowledge and insufficient psychological coping strategies to the disease were very obvious under the overwhelming circumstances. Secondly, since the infrastructure and capability of the healthcare systems varies in different countries, the psychological reaction of health care professionals may differ during an outbreak of an infectious disease. However, another study among Chinese medical care workers also revealed a prevalence of depression, anxiety and stress symptoms, which was even higher than in this study, thus further indicated the factual psychological status in this population at the beginning of the COVID19 outbreak [27].

Posttraumatic stress disorder (PTSD) is a common mental disorder manifesting through symptoms of intrusion, hyperarousal and avoidance following a traumatic event [28]. According to earlier studies, medical care workers are likely to develop adverse psychological problems, such as depression and post-traumatic stress as a result of their trauma experience $[8,29]$. Under the circumstances of an infectious disease outbreak, the frontline medical care workers always have fears of being infected or infecting others, especially when they experience any physical symptoms related to the infection $[2$, $8,30]$. Meanwhile, with the lockdown of cities or even countries due to the COVID outbreak, the medical care workers became obviously the high-risk population to transmit the virus to whom have close contacts with them, and unsurprisingly, were under the situation of being stigmatized or distanced by others. In our study, EFA yielded three dimensions from the 8 perceive threat items, namely stigmatization/distancing, fears of infection and perceived high-risk of their job. These are highly concerned issues by medical care workers in the COVID-19 outbreak and in other similar epidemic, and were proved to be associated with adverse psychological outcomes in this study and previous others, especially PTSD symptoms $[2,6,8,9]$. Therefore, apart from providing appropriate psychological counseling and accurate information targeting the stigmatization against the frontline health care workers to alleviate their perceived threat, a more supportive social environment and more friendly mass media would be helpful to medical care workers' psychological health during an infectious disease outbreak. In addition, while the shortage on medical supplies among medical care workers is not very common in China in this pandemic, it is still worth considering in other countries and in future similar scenario, it may cause severe adverse psychological outcomes among them, even committing suicide.

Active coping strategies focusing on problem-solving can result in an improvement of person-environment relationship and thus lead to a positive emotional response [20]. Our data suggested strategies promoting active coping styles and providing sufficient social support may help to decrease the occurrence of adverse psychological symptoms like depression, anxiety and stress. This is consistent with the previous studies that active coping and social support were the most important buffering factors of negative psychological health among medical care workers [31, 32]. Our study also revealed passive coping strategies mainly focusing on the emotional distress were significantly related to a worse psychological health including PTS, depression, anxiety and stress 
symptoms. It can be explained that passive coping may lead to additional emotional exhaustion apart from the original stressful situation $[22,31]$. The findings that active coping was not significantly related to PTSD symptoms demonstrated the importance of reducing passive coping strategies on PTSD among medical care workers in this extreme situation occurred very rarely in recent years and people have not prepared well to the pandemic both mentally and materially.

In this study, we found nurses were more likely to have anxiety symptoms compare to others. It can be easily interpreted that the nurses always contact patients with different illness, with various social-economic status, and directly access the patients' blood sample, hence have the highest risk of being infected by the COVID-19 virus. Therefore, the occupational role of medical care workers should be considered in future outbreaks and the employers should encourage a supportive workplace to minimize the adverse psychological impact, and pay attention to the medical care worker with the most patient contact and most at risk [33]. Meanwhile, special attention should be taken to those with confirmed cases in their living community or among their acquaintances, they always have higher levels of concern to the epidemic, and hence prone to have adverse psychological symptoms.

Although current tobacco users were less likely to have PTS in our study, we could not agree that smoking is a proper way to alleviate PTS. A study recently published indicated that post-trauma anhedonia (PTA) is associated with increased substance use in a recentlytraumatized population and PTA may be a mechanism through which substance use problems emerge in recently-traumatized individuals [34]. To those experienced PTS, caution should be taken to monitor their tobacco and substance use behaviour when taking care of their psychological health in the aftermath of a trauma event, since cigarettes and marijuana are very easy to be accessed in many countries for general people, not mention to the medical care workers.

Given the amount of stress experienced by the medical care workers during the pandemic, it is important to provide tailored mental health support to them, such as observing the trajectory changes of the post-pandemic mental health situation and establishing a nationwide psychological support group, to avoid the occurrence of widespread psychiatric disorders in this population. Otherwise, it would be a noticeable social and economic burden in the long run [35]. In addition, appropriate intervention measures should be adopted based on the psychological assessment in each stage of the pandemic, including timely counselling and screening, development of positive coping strategies, and create a more friendly social environment and mass media network. This would be applicable to similar epidemics in the future.
This study has several limitations. Since this is the first study of IES-6 utilized in Chinese medical care workers during the ongoing COVID-19 epidemic, the assessment of PTS symptoms using the cut-off value suggested in earlier studies does not necessarily accurate to suggest a clinical diagnosis of PTSD. Still, it can be a measure to identify those with significant PTS for further PTSD assessment and intervention. In addition, while we performed an EFA for extracting factors of perceived threat and proved an acceptable reliability and validity for further multivariate analysis, a more complicated validation analysis including confirmatory factor analysis (CFA) and others should be conducted in current sample and other study in the future. Furthermore, since this is a cross-sectional study conducted during the period when the COVID-19 outbreak was on a downward trend, caution should be made on causal relationships without further follow-up research. Despite the above limitations, the current study provided valuable information of the psychological reactions of medical care workers in China during the outbreak of COVID-19. Our results can provide references and guidance for future psychological interventions targeting this population.

In summary, adverse psychological symptoms were prevalent among medical care workers in China during the COVID-19 epidemic and a screening for PTS would be helpful to identify those might develop PTSD in the following months or years. The medical care workers experienced numerous threats including stigmatization, risk of being infected or infecting others, lack of necessary medical supplies and overwhelming workload. Lack of social support and maladaptive coping were important risk factors for occurrence of negative psychological outcomes among them. Preventive measures and mitigation strategies among medical care workers to prevent early traumatic stress reactions developing into chronic PTSD would be beneficial in decreasing adverse psychological outcomes [36].

\section{Conclusions}

Adverse psychological symptoms were prevalent among medical care workers in China during the COVID-19 epidemic. Screening for adverse psychological outcomes and developing corresponding preventive measures would be beneficial in decreasing negative psychological outcomes of COVID-19 pandemic among medical care workers.

\section{Supplementary information}

Supplementary information accompanies this paper at https://doi.org/10 1186/s40249-020-00724-0.

\section{Additional file 1.}

\section{Abbreviations}

COVID-19: Coronavirus disease 2019; IES-6: Impact of Event Scale-6; IES-

R: Impact of Event Scale-revised; DASS: Depression, Anxiety and Stress Scale; 
PTS: Posttraumatic stress; PTSD: Posttraumatic stress disorder; SARS: Severe acute respiratory syndrome; MERS: Middle East respiratory syndrome; ASD: Acute stress disorder; WHO: World Health Organization; PCL-C: Post Traumatic Stress Disorder Check List - Civilian version; PSSS: The perceived social support scale; SCSQ: Simplified Coping Style Questionnaire; AC: Active coping; PC: Passive coping; EFA: Exploratory factor analysis;

CFA: Confirmatory factor analysis

\section{Acknowledgements}

Not applicable.

\section{Authors' contributions}

Xiao-You Su, Ming-Yu Si prepared the first draft. You-Lin Qiao provided overall guidance. You-Lin Qiao, Xiao-You Su, Wen-Jun Wang and Ming-Yu Si managed the overall project. Xiao-You Su, Wen-Jun Wang, Xiao-Fen Gu, Li Ma, Jing Li, Shao-Kai Zhang and Ze-Fang Ren were responsible for the questionnaire survey of people in seven geographical regions of China. Xiao-You Su and Ming-Yu Si analyzed data. Yu Jiang, Yuan-Li Liu and Ran Ren finalized the manuscript on the basis of comments from other authors. The author(s) read and approved the final manuscript.

\section{Funding}

Asian Regional Special Cooperation Fund of National Health Commission of the People's Republic of China and the Innovative Engineering Program on global health policy sponsored by Chinese Academy of Medical Sciences (2017-I2M-B\&R-17).

\section{Availability of data and materials}

The original data generated from this study and the analyzed results will be available from the corresponding author upon reasonable request.

\section{Ethics approval and consent to participate}

This study has been approved by the Ethics Committee of Jining Medical University of Shandong Province on February 12th, 2020 (approval number: JNMC-2020-KY-001).

\section{Consent for publication}

Not applicable.

\section{Competing interests}

The authors declare that they have no competing interests.

\section{Author details}

'Department of Epidemiology and Biostatistics, School of Population Medicine and Public Health, Chinese Academy of Medical Sciences and Peking Union Medical College, Beijing, China. ${ }^{2}$ School of Nursing, Jining Medical University, Jining, Shandong, China. ${ }^{3}$ Affiliated Tumor Hospital, Xinjiang Medical University, Urumqi, China. ${ }^{4}$ Public Health School, Dalian Medical University, Dalian, China. ${ }^{5}$ West China School of Public Health, Sichuan University/West China Forth Hospital, Sichuan University, Chengdu, China. ${ }^{6}$ Henan Cancer Hospital, Affiliate Cancer Hospital of Zhengzhou University, Zhengzhou, China. ${ }^{7}$ School of Public Health, Sun Yat-sen University, Guangzhou, China. ${ }^{8}$ Global Health Research Center, Dalian Medical University, Dalian, China. ${ }^{9}$ School of Health Management and Policy, Chinese Academy of Medical Sciences and Peking Union Medical College, Beijing, China. ${ }^{10}$ Department of Cancer Epidemiology, National Cancer Center/ National Clinical Research Center for Cancer/Cancer Hospital, Chinese Academy of Medical Sciences and Peking Union Medical College, 17 South Panjiayuan, Chaoyang District, Beijing, China.

\section{Received: 2 May 2020 Accepted: 14 July 2020}

\section{Published online: 12 August 2020}

\section{References}

1. WHO. Situation report-101 of Coronavirus disease 2019 (COVID-19), 2020. https://www.who.int/docs/default-source/coronaviruse/situation-reports/202 00430-sitrep-101-covid-19.pdf?sfvrsn=2ba4e093_2. Accessed 2 May 2020.

2. Brooks SK, Webster RK, Smith LE, Woodland L, Wessely S, Greenberg N, et al. The psychological impact of quarantine and how to reduce it: rapid review of the evidence. Lancet. 2020;395(10227):912-20. https://doi.org/10.1016/ s0140-6736(20)30460-8.
3. Tam CW, Pang EP, Lam LC, Chiu HF. Severe acute respiratory syndrome (SARS) in Hong Kong in 2003: stress and psychological impact among frontline healthcare workers. Psychol Med. 2004;34(7):1197-204. https://doi.org/10.1017/s0033291704002247.

4. Lee SM, Kang WS, Cho AR, Kim T, Park JK. Psychological impact of the 2015 MERS outbreak on hospital workers and quarantined hemodialysis patients. Compr Psychiatry. 2018;87:123-7. https://doi.org/10.1016/j. comppsych.2018.10.003.

5. Raven J, Wurie H, Witter S. Health workers' experiences of coping with the Ebola epidemic in Sierra Leone's health system: a qualitative study. BMC Health Serv Res. 2018;18(1):251. https://doi.org/10.1186/s12913-018-3072-3.

6. Lancee WJ, Maunder RG, Goldbloom DS, Study S. Prevalence of psychiatric disorders among Toronto hospital workers one to two years after the SARS outbreak. Psychiatr Serv. 2008;59(1):91-5. https://doi.org/10.1176/appi.ps.59.1.91.

7. Bryant RA. Acute stress disorder as a predictor of posttraumatic stress disorder: a systematic review. J Clin Psychiatry. 2011;72(2):233-9. https://doi.org/10.4088/JCP.09r05072blu.

8. Bai Y, Lin CC, Lin CY, Chen JY, Chue CM, Chou P. Survey of stress reactions among health care workers involved with the SARS outbreak. Psychiatr Serv. 2004;55(9):1055-7. https://doi.org/10.1176/appi.ps.55.9.1055.

9. Jalloh MF, Li W, Bunnell RE, Ethier KA, O'Leary A, Hageman KM, et al. Impact of Ebola experiences and risk perceptions on mental health in Sierra Leone, July 2015. BMJ Glob Health. 2018;3(2):e000471. https://doi.org/10.1136/ bmjgh-2017-000471

10. Ahmadian A, Mirzaee J, Omidbeygi M, Holsboer-Trachsler E, Brand S. Differences in maladaptive schemas between patients suffering from chronic and acute posttraumatic stress disorder and healthy controls. Neuropsychiatr Dis Treat. 2015;11:1677-84. https://doi.org/10.2147/ndt. S85959.

11. Meli L, Birk J, Edmondson D, Bonanno GA. Trajectories of posttraumatic stress in patients with confirmed and rule-out acute coronary syndrome. Gen Hosp Psychiatry. 2020;62:37-42. https://doi.org/10.1016/j.genhosppsych. 2019.11.006.

12. Thoresen S, Tambs K, Hussain A, Heir T, Johansen VA, Bisson J. Brief measure of posttraumatic stress reactions: impact of event Scale-6. Soc Psychiatry Psychiatr Epidemiol. 2010;45(3):405-12. https://doi.org/10.1007/ s00127-009-0073-x.

13. Zhang MW, Ho C, Fang P, Lu Y, Ho RC. Usage of social media and smartphone application in assessment of physical and psychological wellbeing of individuals in times of a major air pollution crisis. JMIR Mhealth Uhealth. 2014;2(1):e16. https://doi.org/10.2196/mhealth.2827.

14. Lovibond PF, Lovibond SH. The structure of negative emotional states: comparison of the depression anxiety stress scales (DASS) with the Beck depression and anxiety inventories. Behav Res Ther. 1995;33(3):335-43. https://doi.org/10.1016/0005-7967(94)00075-u.

15. Taouk M, Lovibond P, Laube R. Psychometric properties of a Chinese version of the 21-item Depression Anxiety Stress Scales(DASS21). Sydney: Transcultural Mental Health Centre. Cumberland Hospital [N]; 2001.

16. Chan RC, Xu T, Huang J, Wang Y, Zhao Q, Shum DH, et al. Extending the utility of the depression anxiety stress scale by examining its psychometric properties in Chinese settings. Psychiatry Res. 2012;200(2-3):879-83. https://doi.org/10.1016/j.psychres.2012.06.041.

17. Wang K, Shi HS, Geng FL, Zou LQ, Tan SP, Wang Y, et al. Cross-cultural validation of the depression anxiety stress Scale-21 in China. Psychol Assess. 2016;28(5):e88-e100. https://doi.org/10.1037/pas0000207.

18. Zimet GD, Powell SS, Farley GK, Werkman S, Berkoff KA. Psychometric characteristics of the multidimensional scale of perceived social support J Pers Assess. 1990;55(3-4):610-7. https://doi.org/10.1080/00223891.1990. 9674095.

19. Chou KL. Assessing Chinese adolescents' social support: the multidimensional scale of perceived social support. Personal Individ Differ. 2000;28(2):299-307. https://doi.org/10.1016/S0191-8869(99)00098-7.

20. Folkman S, Lazarus RS. Coping as a mediator of emotion. J Pers Soc Psychol 1988;54(3):466-75. https://doi.org/10.1037/0022-3514.54.3.466.

21. Xie Y. Reliability and validity of the simplified Coping Style Questionnaire. [Reliability and validity of the simplified Coping Style Questionnaire]. Chinese J Clin Psychol. 1998;6(2):114-5. https://doi.org/10.16128/j.cnki.10053611.2018.05.015.

22. Kraaij V, Garnefski N, Maes S. The joint effects of stress, coping, and coping resources on depressive symptoms in the elderly. Anxiety Stress \& Coping. 2002;15(2):163-77. https://doi.org/10.1080/10615800290028468. 
23. Comrey AL, Lee HB. A first course in factor analysis. 2nd ed. New York: Psychology Press; 1992. https://doi.org/10.4324/9781315827506.

24. Wu P, Fang Y, Guan Z, Fan B, Kong J, Yao Z, et al. The psychological impact of the SARS epidemic on hospital employees in China: exposure, risk perception, and altruistic acceptance of risk. Can J Psychiatr. 2009;54(5):302-11. https://doi.org/10.1177/070674370905400504.

25. Ren X, Yu S, Dong W, Yin P, Xu X, Zhou M. Burden of depression in China, 1990-2017: findings from the global burden of disease study 2017. J Affect Disord. 2020;268:95-101. https://doi.org/10.1016/j.jad.2020.03.011.

26. Chew NWS, Lee GKH, Tan BYQ, Jing M, Goh Y, Ngiam NJH, et al. A multinational, multicentre study on the psychological outcomes and associated physical symptoms amongst healthcare workers during COVID-19 outbreak. Brain Behav Immun. 2020. https://doi.org/10.1016/j.bbi.2020.04.049.

27. Liu S, Yang L, Zhang C, Xiang YT, Liu Z, Hu S, et al. Online mental health services in China during the COVID-19 outbreak. Lancet Psychiatry. 2020; 7(4):e17-e8. https://doi.org/10.1016/s2215-0366(20)30077-8.

28. Astill Wright L, Sijbrandij M, Sinnerton R, Lewis C, Roberts NP, Bisson Jl. Pharmacological prevention and early treatment of post-traumatic stress disorder and acute stress disorder: a systematic review and meta-analysis. Transl Psychiatry. 2019;9(1):334. https://doi.org/10.1038/s41398-019-0673-5.

29. Wu P, Liu X, Fang Y, Fan B, Fuller CJ, Guan Z, et al. Alcohol abuse/ dependence symptoms among hospital employees exposed to a SARS outbreak. Alcohol Alcohol. 2008;43(6):706-12. https://doi.org/10.1093/alcalc/ agn073.

30. Maunder R, Hunter J, Vincent L, Bennett J, Peladeau N, Leszcz M, et al. The immediate psychological and occupational impact of the 2003 SARS outbreak in a teaching hospital. CMAJ. 2003;168(10):1245-51 PMID: 12743065.

31. Li X, Guan L, Chang H, Zhang B. Core self-evaluation and burnout among nurses: the mediating role of coping styles. PLoS One. 2014;9(12):e115799. https://doi.org/10.1371/journal.pone.0115799.

32. Garrosa E, Rainho C, Moreno-Jiménez B, Monteiro MJ. The relationship between job stressors, hardy personality, coping resources and burnout in a sample of nurses: a correlational study at two time points. Int J Nurs Stud. 2010;47(2):205-15. https://doi.org/10.1016/j.jpurstu.2009.05.014.

33. Brooks SK, Dunn R, Amlôt R, Rubin GJ, Greenberg N. A systematic, thematic review of social and occupational factors associated with psychological outcomes in healthcare employees during an infectious disease outbreak. J Occup Environ Med. 2018;60(3):248-57. https://doi.org/10.1097/jom. 0000000000001235.

34. Fani N, Jain J, Hudak LA, Rothbaum BO, Ressler KJ, Michopoulos V. Posttrauma anhedonia is associated with increased substance use in a recentlytraumatized population. Psychiatry Res. 2020;285:112777. https://doi.org/10. 1016/j.psychres.2020.112777.

35. Sani G, Janiri D, Di Nicola M, Janiri L, Ferretti S, Chieffo D. Mental health during and after the COVID-19 emergency in Italy. Psychiatry Clin Neurosci. 2020;74(6):372. https://doi.org/10.1111/pcn.13004.

36. Naushad VA, Bierens JJ, Nishan KP, Firjeeth CP, Mohammad OH, Maliyakkal AM, et al. A systematic review of the impact of disaster on the mental health of medical responders. Prehosp Disaster Med. 2019:34(6):632-43. https://doi.org/10.1017/s1049023×19004874.

Ready to submit your research? Choose BMC and benefit from:

- fast, convenient online submission

- thorough peer review by experienced researchers in your field

- rapid publication on acceptance

- support for research data, including large and complex data types

- gold Open Access which fosters wider collaboration and increased citations

- maximum visibility for your research: over $100 \mathrm{M}$ website views per year

At BMC, research is always in progress.

Learn more biomedcentral.com/submissions 